JURNAL ILMIAH MANAJEMEN DAN KEWIRAUSAHAAN Vol 1,No.1, Mei 2021, pp. 17 - 32

p-ISSN : 2808-876X (print)

e-ISSN : 2798-1312 (online)

http://journal.politeknik-pratama.ac.id/index.php/IMK

page 17

\title{
PEMBUATAN MULTIMEDIA COMPANY PROFILE CV. SARANA WIJAYA SEBAGAI MEDIA INFORMASI
}

\author{
Edy Siswanto $^{1}$, Robby Andika Kusumajaya ${ }^{2}$, Nining Fitriani ${ }^{3}$ \\ ${ }^{1}$ Universitas Stekom, email: edy@ stekom.ac.id \\ ${ }^{2}$ Universitas Stekom, email : robby@ stekom.ac.id \\ ${ }^{3}$ Universitas Stekom, email : ningjeporo@gmail.com
}

\section{ARTICLE INFO}

Article history:

Received 28 April 2021

Received in revised form 5 Mei 2021

Accepted 20 Mei 2021

Available online 1 Juni 2021

\begin{abstract}
CV. Sarana Wijaya is a limited liability company for the procurement of construction goods and services founded by Mr. Tri Pudjiarso and Mrs. Anik Purwamti. On December 21, 2009 in Semarang. CV. Sarana Wijaya is located at Jl. West Cinde 9 No. 15 Semarang. The purpose and objective of this company is to run a business that is engaged in establishing and operating companies in the construction of buildings, housing, bridges, roads, railways, dams, reclamation, dredging, docks, drainage, and landscaping. (landscaping) and interior design. The research methodology used by the author is descriptive research type and the research specifications used by the author are descriptive qualitative research. The data source used by the author is the premier data source
\end{abstract}

Keywords : Profile Company, Multimedia

\begin{abstract}
Abstrak
CV. Sarana Wijaya adalah sebuah perseroan komanditer pengadaan barang dan jasa konstruksi yang didirikan oleh Bapak Tri Pudjiarso dan Ibu Anik Purwamti. Pada tanggal 21 Desember 2009 di Semarang. CV. Sarana Wijaya beralamat di Jl. Cinde Barat 9 No. 15 Semarang. Maksud dan tujuan dari perseroan ini yaitu menjalankan usaha yang bergerak dalam bidang mendirikan serta mengusahakan perusahaanperusahaan dalam bidang pemborong banguan gedung, perumahan, jembatan, jalan raya, jalan kereta api, bendungan-bendungan, reklamasi, pengerukan, dermaga, drainase, dan pertamanan (landscaping) serta interior desain. Metodelogi penelitian yang di gunakan penulis yaitu tipe penelitian deskriptif dan spesifikasi penelitian yang di gunakan penulis adalah penelitian deskriptif kualitatif. Sumber data yang di gunakan penulis adalah sumber data premier
\end{abstract}

\section{PENDAHULUAN}

Sekarang ini perkembangan teknologi berkembang semakin pesat, terutama dibidang teknologi komputerisasi. Dengan perkembangan teknologi dapat merubah pola pikir manusia untuk lebih praktis dan logis. Suatu informasi dapat lebih jelas apabila ditampilkan dalam media yang dapat menggabungkan berbagai bentuk informasi yang telah ada. Dengan adanya media company profile perusahaan dapat berinteraksi dengan konsumen melalui media teks, gambar, audio, video, dan juga animasi sebagai informasi yang disajikan dimana informasi yang dihasilkan akan lebih jelas dan menarik. Media ini juga dapat digunakan pada bidang pemasaran, publikasi, dan lain-lain. Khususnya untuk bidang pemasaran. Media company profile merupakan salah satu media pendukung yang sangat penting dalam penyampaian informasinya. (Hanif Al Fatta,2007)

CV. Sarana Wijaya berdiri pada tanggal 21 Desember 2009 yang beralamat di jalan Cinde Barat IX No. 25 Semarang. CV. Sarana Wijaya sebagai perusahaan yang bergerak di bidang pengadaan barang dan jasa konstruksi. Diantaranya mendirikan serta mengusahakan perusahaan-perusahaan dalam bidang pemborong bangunan gedung, perumahan, jembatan, jalan raya bendungan, reklamasi, pengerukan, serta interior desain. Pengadaan barang dan jasa termasuk alat atau peralatan suku cadang, alat berat konstruksi, dan lain-lain. CV. Sarana Wijaya mempunyai 5 karyawan inti dan semua ahli dibidangnya. 
Media promosi yang selama ini digunakan oleh CV. Sarana Wijaya dengan buku company profile dan sistem marketing secara lisan yaitu dengan cara menawarkan secara langsung kepada client. Sehingga hal ini menjadi kendala perusahaan dalam mempromosikan produknya. Waktu yang singkat tidak dapat menjelaskan produk dan perusahaan secara lengkap. Media yang mampu mewujudkan hal tersebut adalah media yang dikemas dalam sebuah

multimedia. Karena media ini memiliki kelebihan untuk interaktif dibanding buku company profile, disamping itu keberadaan dari multimedia juga sangat diperlukan untuk memberikan informasi yang kompleks dalam mendukung presentasi serta menjalin dengan pihak lain.

Semakin besar dan bonafid client yang pernah diajak kerjasama, semakin mengangkat nilai dari perusahaan tersebut. Karena hal ini menunjukkan bahwa perusahaan tersebut sudah diakui kinerjanya oleh client yang memiliki nama besar. CV. Sarana Wijaya sering mendapat proyek dari Pemkot Kota Semarang oleh karena itu CV. Sarana Wijaya mempunyai kredibilitas yang cukup baik. Proyek Pemkot Kota Semarang yang selama satu tahun kebelakang yang di kerjakan oleh CV. Sarana Wijaya antara lain:

1. Kegiatan Pavingisasi J1. RT.5 RW.2 Kel. Bangetayu Wetan Kec. Genuk DTKP Kota Semarang

2. Peninggian \& PavingisasiI JL. Wonomulyo Mukti Timur RW.11 KEL. Tlogomulyo Kec. Pedurungan

3. Pekerjaan Pengecatan Interior Ruang VIP dan VVIP Di Gedung Geriatri Rumah Sakit Umum DR. Kariyadi Semarang

4. Berbaikan Ruang Genset Rumah Sakit Umum DR. Kariyadi Semarang

5. Pembuatan Pagar Beton Rumah Sakit Umum DR. Kariyadi Semarang

Untuk menambah pengalaman, dan meningkatkan nilai saham perusahaan maka CV. Sarana Wijaya ingin berkembang dan menjadi perusahaan yang besar di Indonesia. CV. Sarana Wijaya memerlukan media promosi yang efektif sebagai sarana mempromosikan perusahaan tersebut dan juga menyampaikan secara jelas tentang profil perusahaan, direktur, visi misi, tujuan, peralatan dan gallery pekerjaan informasi lainnya yang berhubungan dengan CV. Sarana Wijaya.

Berkaitan dengan hal yang diuraikan di atas maka penulis ingin membuat tugas akhir yang berjudul "Pembuatan Multimedia Company Profile CV. Sarana Wijaya Sebagai Media Informasi".

\section{LANDASAN TEORI}

\section{Company Profile}

1. Pengertian Company Profile

Company Profile berasal dari bahasa Inggris-bahasa Indonesia. company profile berasal dari dua kata bahasa Inggris yang mempunyai pengertian yang berbeda tapi saling berkaitan, yakni kata "company" dan "profile" dimana kedua kata tersebut dapat kita artikan berdasarkan kamus (John M. Echols dan Hasan Shadily : 131, 449).

a. Arti dari company menurut kamus Bahasa Inggris-Indonesia,

company adalah :

1) Perusahaan, Maskapai, Firma

2) Perseroan

3) Persekutuan

4) Kompi

5) Rombongan

b. Arti dari Profile menurut kamus Bahasa Inggris-Indonesia,

Profile adalah :

1) Tamang atau raut muka

2) Penampang

3) Riwayat

Istilah Company Profile merupakan gambaran umum mengenai suatu media jati diri untuk menyampaikan dan menginformasikan tentang nilai-nilai positif tentang suatu perusahaan, lembaga atau instansi baik pemerintahan maupun swasta, agar mendapatkan suatu tanggapan yang positif (simpati dari masyarakat), sehingga keberadaan perusahaan bisa di terima oleh masyarakat (Muh. Akbar, 2006).

Company Profile adalah informasi data diri atau biografi tentang kegiatan perusahaan yang dilakukan terus menerus, terang-terangaan (legal) yang menyediakan barang dan jasa guna memperoleh keuntungan. Berbagai macam variable pertimbangan dalam memilih tentunya merupakan dasar untuk mengambil keputusan mana yang nantinya akan diambil dalam membuat Company Profile. Adapun variabel tersebut antara lain kebutuhan space yang sesuai, serta 
didukung dengan aplikasi-aplikasi yang mendukung untuk membuat company profile dalam bentuk multimedia, dengan berbagai dukungan dan fasilitas-fasilitas yang diperlukan menjadikan Company Profile bisa lebih mudah di pahami dan dimengerti (Pupung B Purnama, 2006).

Company Profile ini umumnya merupakan informasi tentang data diri sebuah perusahaan, seperti data profile, gagasan atau ide-ide, karya-karya yang telah dibuat serta tujuan dari pembuatan Company Profile. Selain memberi informasi Company Profile juga merupakan media promosi. Pada Company Profile, tidak begitu banya dibutuhkan aplikasi dalam pembuatannya karena karena pembuatannya sangat simple dan sedehana dan mudah penguasaannya. Aplikasi yang digunakan hanya bersifat informasi, komunikasi dan pengenalan produk dan layanan. Sebagian besar perusahaan dalam melakukan promosi sudah banyak yang menggunakan Company Profile. Dan itu hanya menampikan profile perusahaan, visi, misi, dan sejarah perkembangan, organisasi, jasa, dan produk yang ditawarkan dan seterusnya. Dalam Company Profile pengguna biasa langsung mengetahui apa yang terkandung didalamnya yaitu secara langsung menjual jasa atau produknya, tapi hanya sebatas informasi (Pupung B Purnama, 2006).

Company profile merupakan penjelasan mengenai perusahaan termasuk produknya secara verbal maupun grafik yang mengangkat corporate value serta product value serta keunggulan perusahaan dibandingkan pesaing. Company profile merupakan salah satu media public relations yang merepresentasikan sebuah perusahaan (organisasi). Produk public relations ini berisi gambaran umum perusahaan, di mana perusahaan bisa memilih poin-poin apa saya yang ingin disampaikan secara terbuka kepada publiknya disesuaikan dengan kepentingan publik sasaran. Company profile merupakan sebuah paparan dan penjelasan mengenai perusahaan termasuk produknya secara verbal maupun dalam bentuk grafik yang menigkatkan corporate value (nilainilai perusahaan).

Dari pernyataan tersebut dapat disimpulkan bahwa company profile merupakan gambaran umum mengenai suatu jati diri sebuah perusahaan yang berisi keunggulan sebuah perusahaan sehingga orang tertarik untuk melihatnya. Company profile dapat berupa buku, website, dan aplikasi yang dapat menjelaskan tentang bagaimana perusahaan atau organisasi tersebut (Muh. Akbar, 2006),

2. Unsur Company Profile

Menurut sebuah website www.binasyifa.com dalam sebuah company profile terdapat beberapa unsur penting yang harus dicantumkan, unsur-unsur tersebut adalah sebagai berikut:

a. Sejarah berdirinya perusahaan

Perusahaan yang sudah lama berdiri biasanya akan memiliki nilai yang lebih tinggi dari perusahaan yang baru berdiri karena dianggap cukup memiliki banyak pengalaman sehingga memudahkan prosespenyelesaian apabila dalam proses kerjasama terjadi sebuah hambatan.

Selain itu, perusahaan yang lama berdiri dianggap memiliki relasi yang luas sehingga calon konsumen berharap mendapatkan nilai lebih dari kerjasama yang yang dilakukan dengan perusahaan tersebut. Misalnya, mendapatkan relasi baru atau kemudahan dalam kegiatan usahanya.

b. Visi misi usaha

Kesamaan visi dan misi perusahaan akan memudahkan proses kerjasama yang terjadi pada dua perusahaan.

c. Stuktur organisasi

Perusahaan bonafid biasanya memiliki struktur perusahaan yang jelas dan lengkap sehingga masing-masing bagian akan memiliki penanggung jawab tersendiri dan tidak terjadi penumpukan tanggung jawab.

d. Sumber daya manusia

Latar belakang sumber daya manusia, memiliki peranan penting dalam menentukan kualitas perusahaan itu sendiri. Perusahaan yang berisi para sarjana tentunya akan lebih bonafid dibandingkan dengan perusahaan yang berisi para lulusan SMA.

e. Sumber daya perusahaan

Perusahaan yang memiliki reputasi yang baik, tentu akan memiliki perangkat pendukung yang memadai dalam setiap aktivitasnya. Sehingga pada nantinya perangkat tersebut dapat bermanfaat untuk memperlancar aktivitas perusahaan khususnya dalam hal kerjasama. 
f. Kinerja perusahaan

Perusahaan yang baik akan memiliki kinerja yang baik. Salah satu indikatornya adalah mampu memenuhi jadwal yang sudah dirancang dan mencapai target yang sudah ditetapkan. Perusahaan yang memiliki kemampuan seperti ini adalah perusahaan yang memiliki kinerja yang baik dan layak dijadikan refrensi untuk menjalin kerjasama.

g. Klien terdahulu

Gambaran tentang klien yang pernah ditangani oleh perusahaan mampu mengangkat reputasi perusahaan tersebut dalam company profilenya. Semakin besar dan bonafid klien yang pernah diajak kerjasama, semakin mengangkat nilai dari perusahaan tersebut. Karena hal ini menunjukkan bahwa perusahaan tersebut sudah diakui kinerjanya oleh klien yang memiliki nama besar.

h. Pengalaman

Perusahaaan harus mampu mencantumkan kemampuan apa yang menjadi keunggulan perusahaan tersebut. Dalam hal ini, tidak perlu mencantumkan hal-hal yang belum pernah dilakukan karena hanya akan menyebabkan kerugian apabila calon klien mengetahuinya. Akan lebih baik, menyampaikan beberapa jenis pekerjaan yang sudah pernah dijalankan dengan hasil yang sesuai harapan.

i. Portofolio perusahaan

Adalah kumpulan informasi yang berupa data serta dokumentasi dari setiap prestasi atau karya yang sudah pernah dicapai perusahaan (Binasyifa, 2015).

\section{Kriteria Company Profile}

Menurut sebuah website http://takeitfun.blogdetik.com selain memenuhi unsur-unsur yang telah ditentukan diatas, sebuah company profile juga harus memiliki kriteria lain agar dapat menarik minat audience untuk membacan, kriteria tersebut adalah sebagai berikut:

a. Representatif

Desain company profile pertama-tama harus representatif, sesuai dengan kesan, karakter dan image yang telah dibangun dan ingin ditampilkan oleh perusahaan. Umumnya kesan, karakter dan image yang ditampilkan pada company profile itu formal/resmi, konservatif, profesional, punya integritas, kredibel dan akuntabel.

Tetapi ada juga perusahaan yang ingin lebih kelihatan casual, dinamis, egaliter, ramah, hangat dan akrab, berani tampil beda sambil tetap menjaga profesionalitas, integritas, kredibilitas dan akuntabilitas. Pada akhirnya yang menentukan kesan, karakter dan image seperti apa yang akan ditampilkan adalah sifat dari bisnis yang dijalankan oleh perusahaan (company profile sebuah law firm, misalnya, pasti akan berbeda dengan animation house), atau preferensi dari top decision maker dalam perusahaan tersebut. Sering ditemukan company profile sebuah perusahaan yang desainnya sangat tidak biasa, karena top decision makernya memang menginginkan hal yang seperti itu.

b. Informatif

Selain representatif, desain company profile juga harus bisa membantu supaya setiap informasi yang ada ditampilkan dengan benar, akurat, dan lengkap, dan disajikan dengan cara yang menarik, jelas dan mudah untuk dimengerti.

Untuk memenuhi kedua hal di atas, pemahaman tentang pemakaian wujud (form) dan ruang (space), tipografi, foto/ilustrasi, warna, dan layout yang tepat memegang peranan yang sangat penting. Selain itu perlu diperhatikan juga cara dan metode distribusi dan penyampaiannya.

c. Struktur

Meski desain sebuah company profile bisa berbeda satu sama lain, tapi struktur isinya pada dasarnya sama. Umumnya company profile memuat hal-hal informatif seperti : sejarah perusahaan, profil perusahaan dan divisi/unit-unit bisnis yang ada, features (tulisan khusus tentang kekhasan perusahaan yang layak untuk diangkat), informasi produk/jasa yang ada dan daftar klien atau proyek yang pernah dilayani atau dikerjakan oleh perusahaan.

Dengan adanya digitalisasi dan teknologi media baru seperti disc dan website, desain company profile sekarang ini sudah semakin dinamis, dengan variasi content yang beragam dan kemudahan untuk mengupdate informasi yang disajikan kapan pun diperlukan (Muh. Akbar, 2006).

4. Tujuan Company Profile 
21

Menurut Muh. Akbar bidang Akademika dan Kemahasiswaan company profile memiliki berbagai fungsi dan tujuan, diantaranya:

a. Memberikan informasi tentang jati diri perusahaan data organisasi.

b. Dapat mengkomunikasikan perusahaan atau organisasi pada khalayak umum sehingga masyarakat memiliki pandangan dan mengerti keberadaan perusahaan atau organisasi tersebut.

c. Dapat memperkenalkan profile perusahaan pada khalayak umum dengan mudah.

d. Untuk memudahkan audience dalam memahami dan mengenal lebih jauh tentang profile perusahaan atau organisasi, yang mana dalam pembuatannya meliputi beberapa media seperti cetak, interaktif, dan lain sebagainya.

e. Membangun citra perusahaan (Muh. Akbar, 2006).

\section{METODE PENELITIAN}

\section{Wawancara / Interview}

Wawancara adalah salah satu bentuk data yang dilakukan dengan jalan tanya jawab yang dikerjakan secara sistematis dan dilandasi pada tujuan penelitian. Wawancara dimaksudkan untuk memperoleh data pendukung guna memperlancar pembuatan tugas akhir, yang diambil dari data primer yaitu data yang diambil penulis dari sumber pertama secara langsung. Data tersebut adalah data-data yang bersangkutan dengan perusahaan diantaranya profil pendiri perusahaan, sejarah perusahaan, tujuan perusahaan.

\section{Observasi / Pengamatan}

Observasi adalah metode pengumpulan data dengan cara melakukan pengamatan secara langsung pada suatu objek yang diteliti serta mencatat dan mengumpulkan data terhadap prosedur-prosedur yang akan dilakukan. Diantaranya diperoleh daari data sekunder, yaitu data yang diperoleh dalam bentuk yang sudah jadi dan sudah diolah serta sudah digunakan sebagai media informasi diantaranya visi \& misi, struktur organisasi, alamat perusahaan, nomor telepon, nomor fax, dan email.

\section{Studi Pustaka}

Studi Pustaka adalah sebuah tekhnik pengumpulan informasi untuk memperoleh data-data beserta memperluas wawasan dengan menggunakan buku, majalah, dan literature diantaranya cara membuat company profile dan teori-teori.

\section{HASIL DAN PEMBAHASAN}

1. Tampilan Akhir Company Profile

a. Tampilan Pembuka

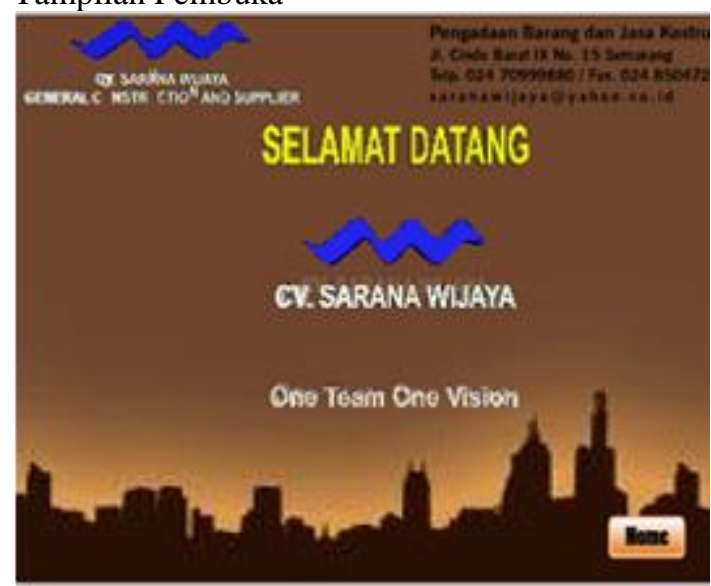

Gambar 4.20 Tampilan Akhir Pembuka 
b. Tampilan Menu Utama

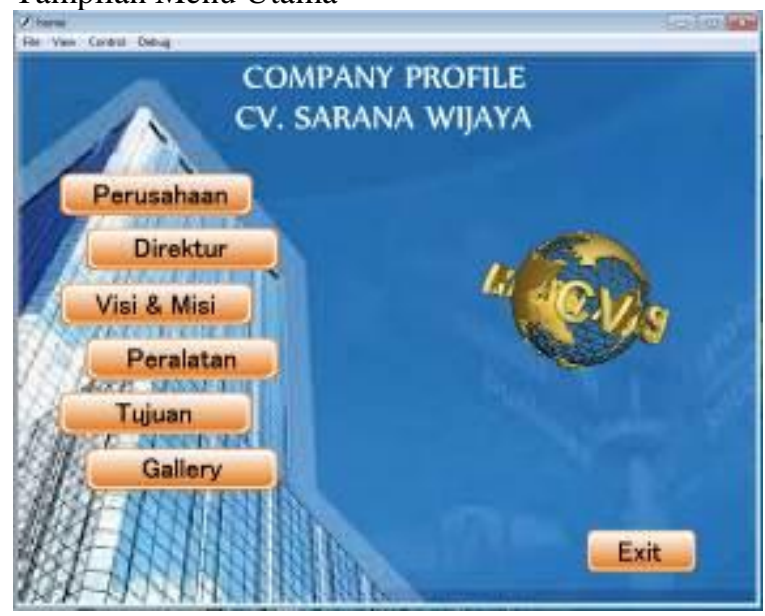

Gambar 4.21 Tampilan Akhir Menu Utama

c. Sub Menu

1) Perusahaan

a) About Us

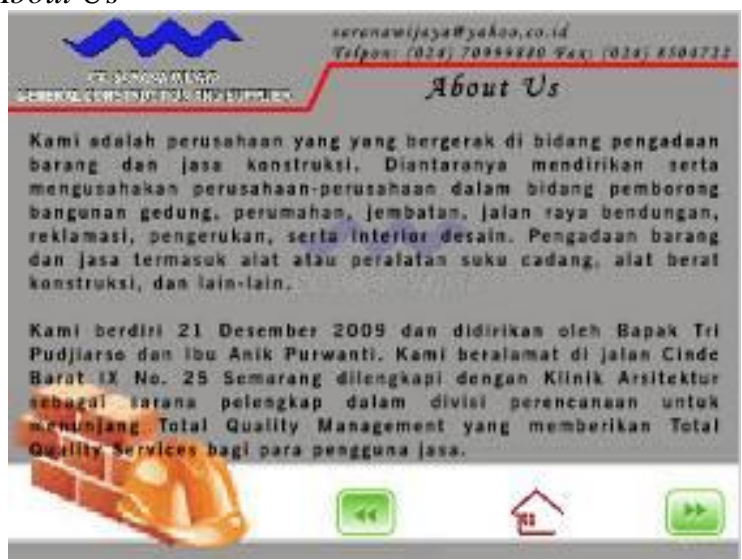

Gambar 4.22 Tampilan Akhir About Us

b) Profil Perusahaan

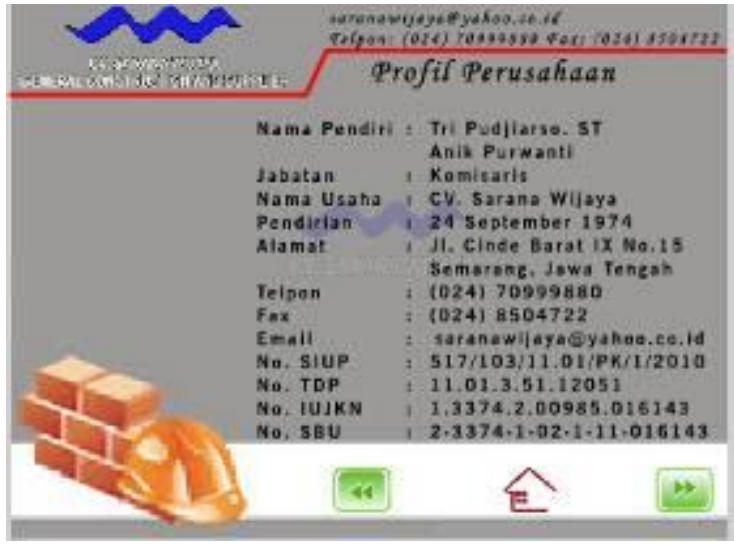

Gambar 4.23 Tampilan Akhir Profil Perusahaan 
c) Karyawan

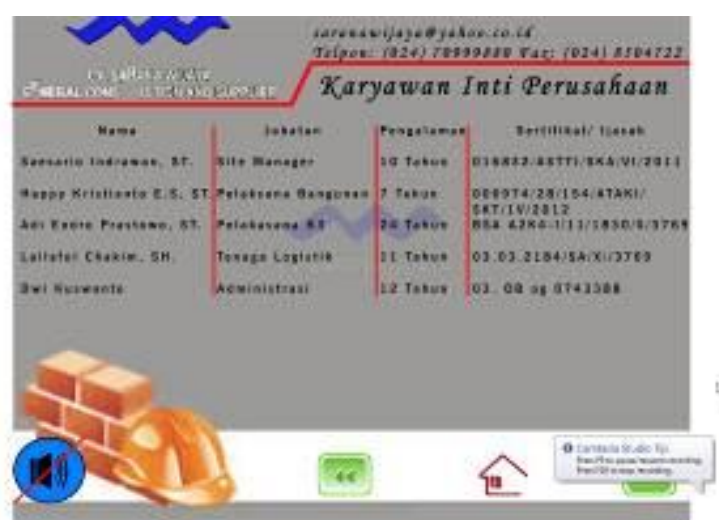

Gambar 4.24 Tampilan Akhir Karyawan

d) Legalitas

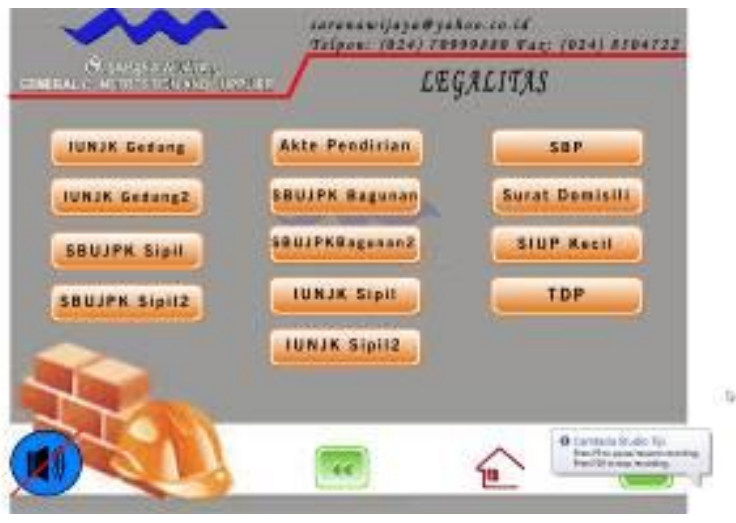

Gambar 4.25 Tampilan Akhir Legalitas

e) Akte Pendirian

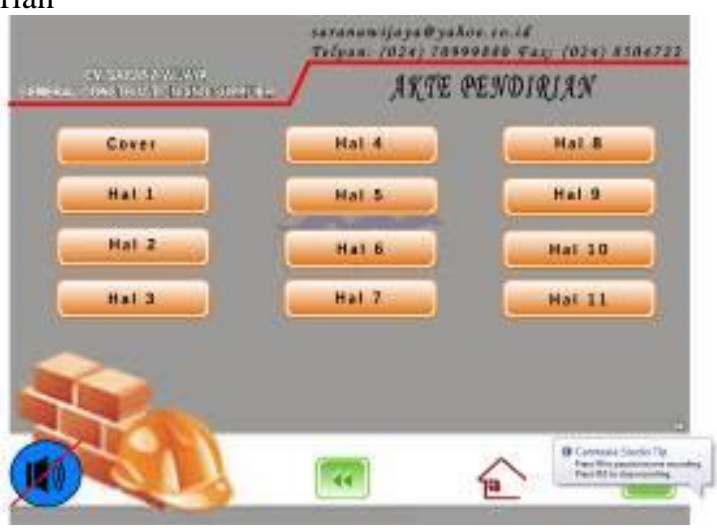

Gambar 4.26 Tampilan Akhir Akte Pendirian 
f) Contact Us

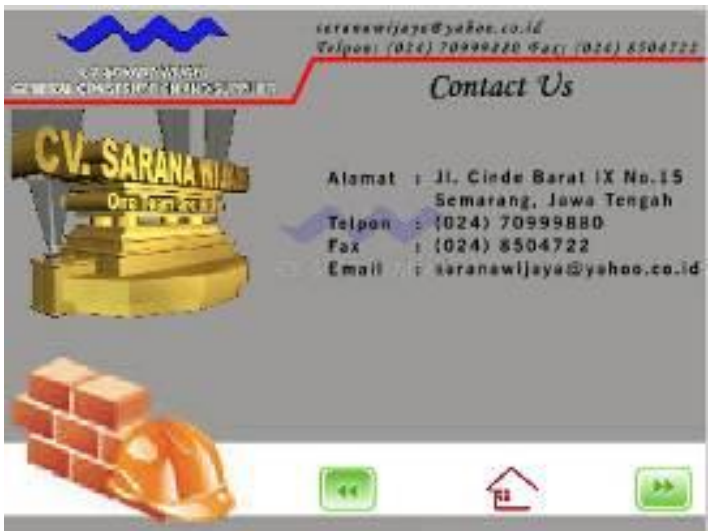

Gambar 4.27 Tampilan Akhir Contact Us

2)

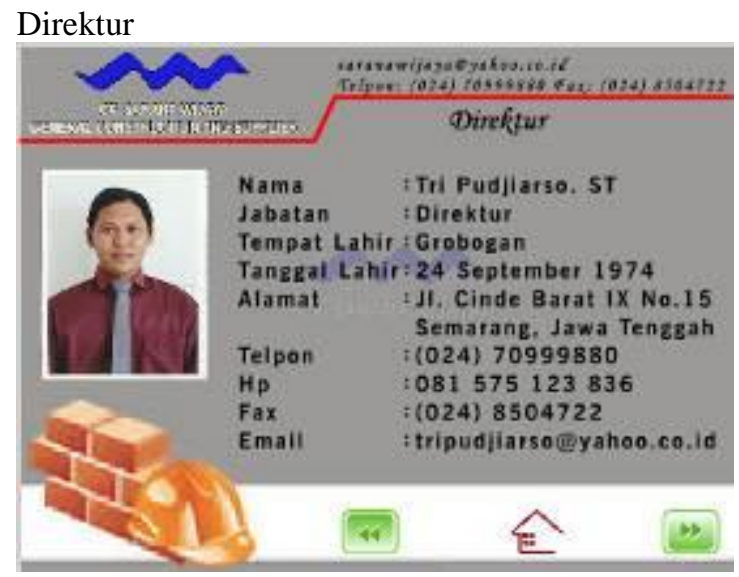

Gambar 4.28 Tampilan Akhir Direktur

3) Visi \& Misi

a) Visi

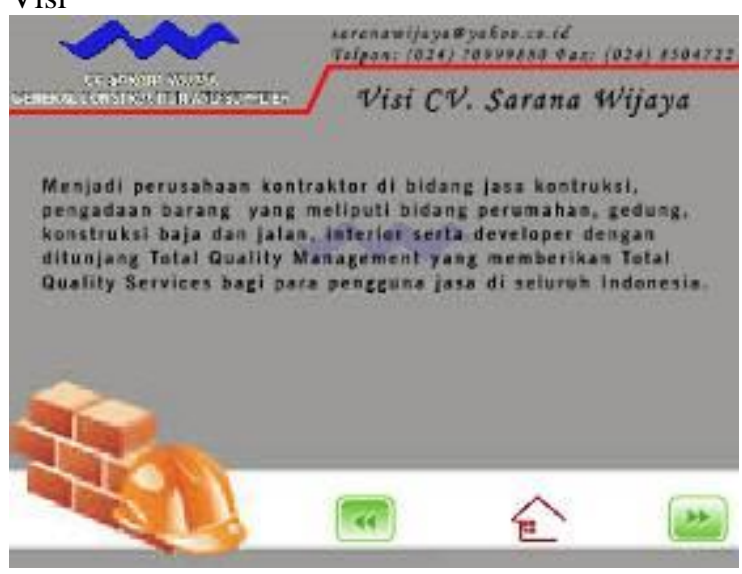

Gambar 4.29 Tampilan Akhir Visi 
b) Misi

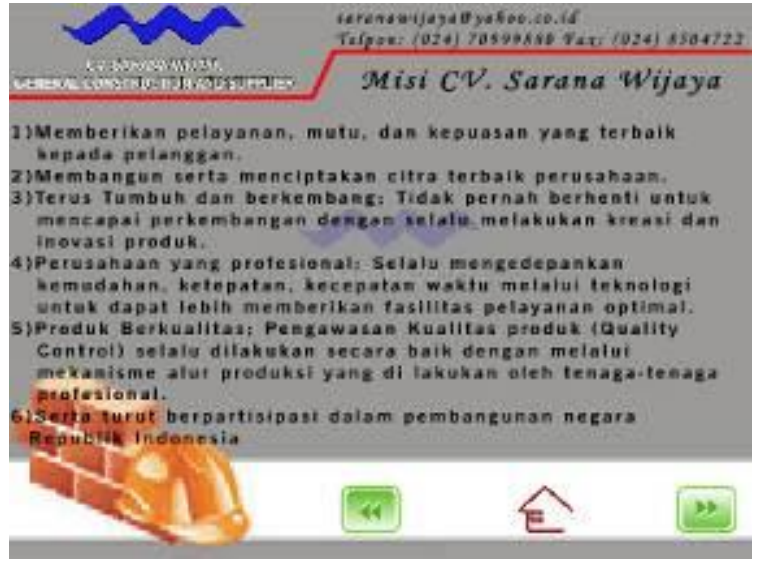

Gambar 4.30 Tampilan Akhir Misi

4) Peralatan

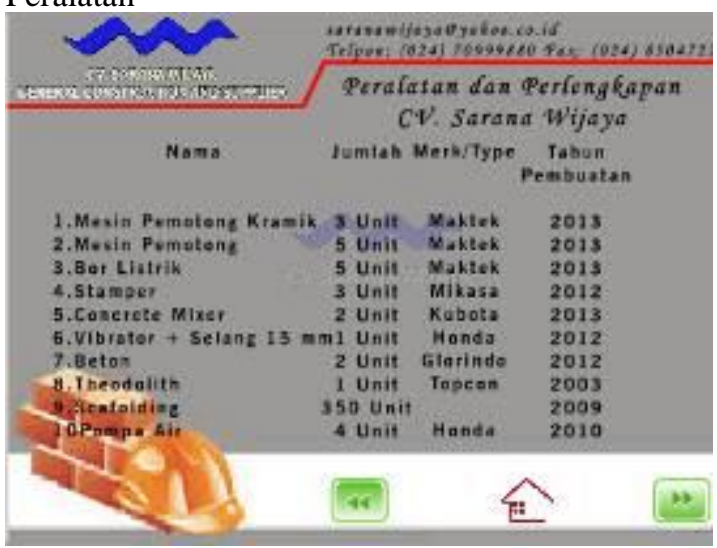

Gambar 4.31 Tampilan Akhir Peralatan

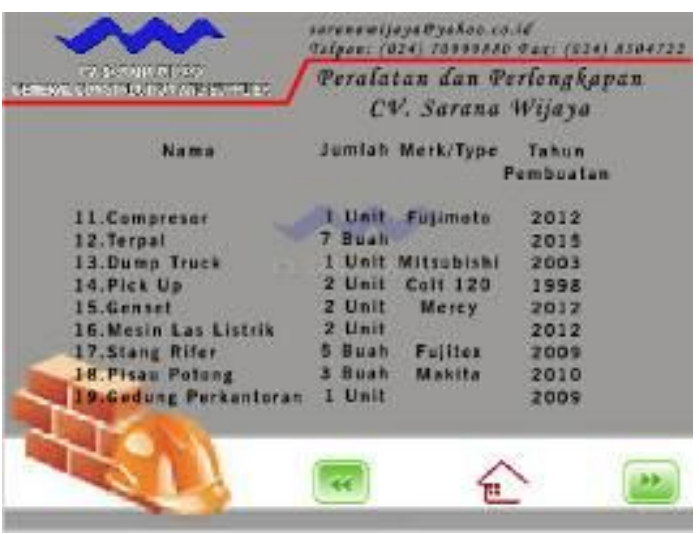

Gambar 4.32 Tampilan Akhir Peralatan 
5)

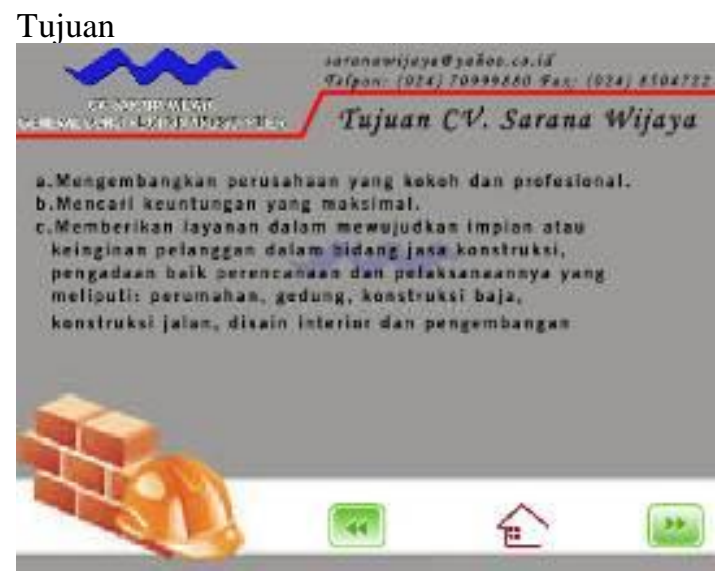

Gambar 4.33 Tampilan Akhir Tujuan

6) Gallery

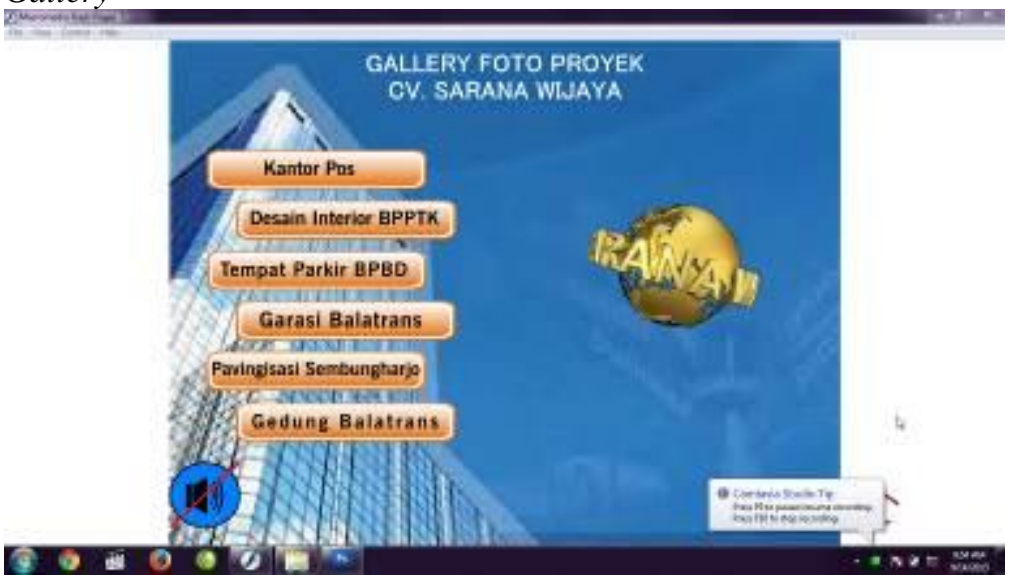

Gambar 4.34 Tampilan Akhir Menu Gallery

a) Kantor Pos

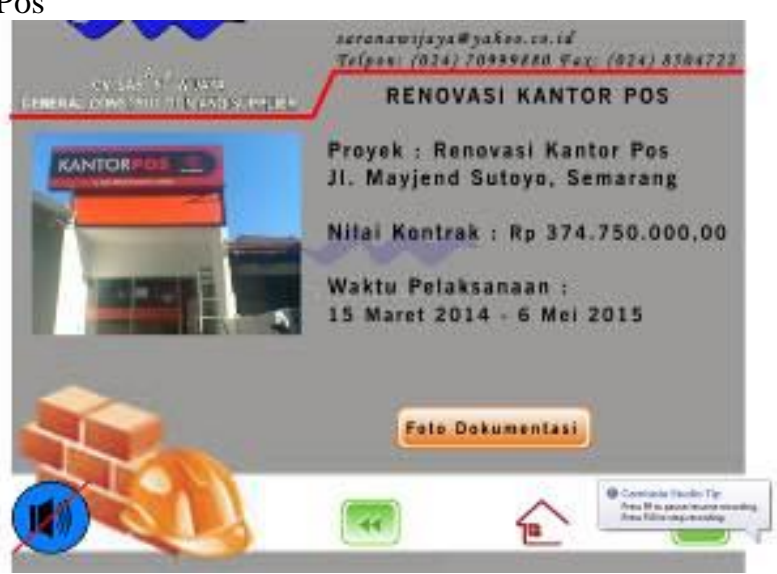

Gambar 4.35 Tampilan Akhir Kantor Pos

b) Foto Dokumentasi Kantor Pos 
27

Jurnal IImiah Manajemen dan Kewirausahaan p-ISSN : 2808-876X e-ISSN : 2798-1312

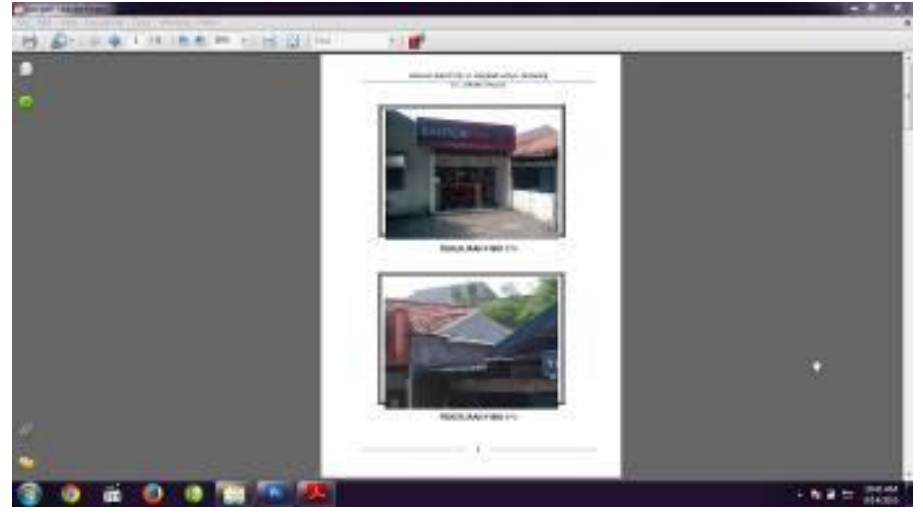

Gambar 4.36 Tampilan Akhir Foto Dokumentasi

Kantor Pos

c) Desain Interior BPPTK

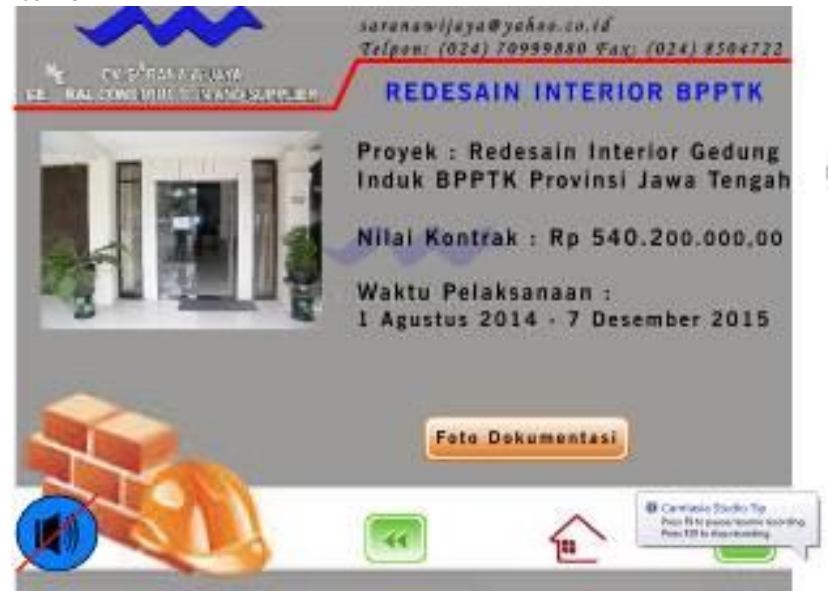

Gambar 4.37 Tampilan Akhir Desain Interior BPPTK

d) Foto Dokumentasi Desain Interior BPPTK

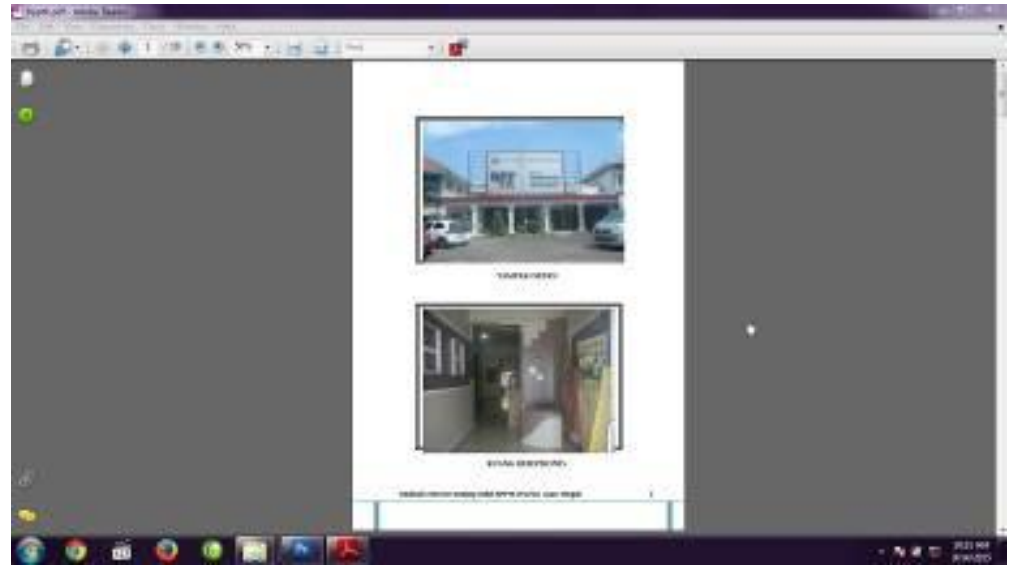

Gambar 4.38 Tampilan Akhir Foto Dokumentasi Desain Interior BPPTK 
e) Tempat Parkir BPBD

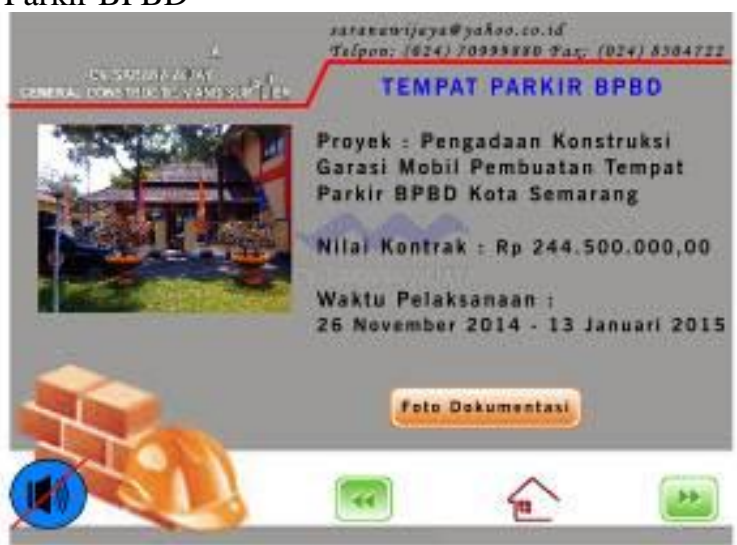

Gambar 4.39 Tampilan Akhir Tempat Parkir BPBD

f) Foto Dokumentasi Tempat Parkir BPBD

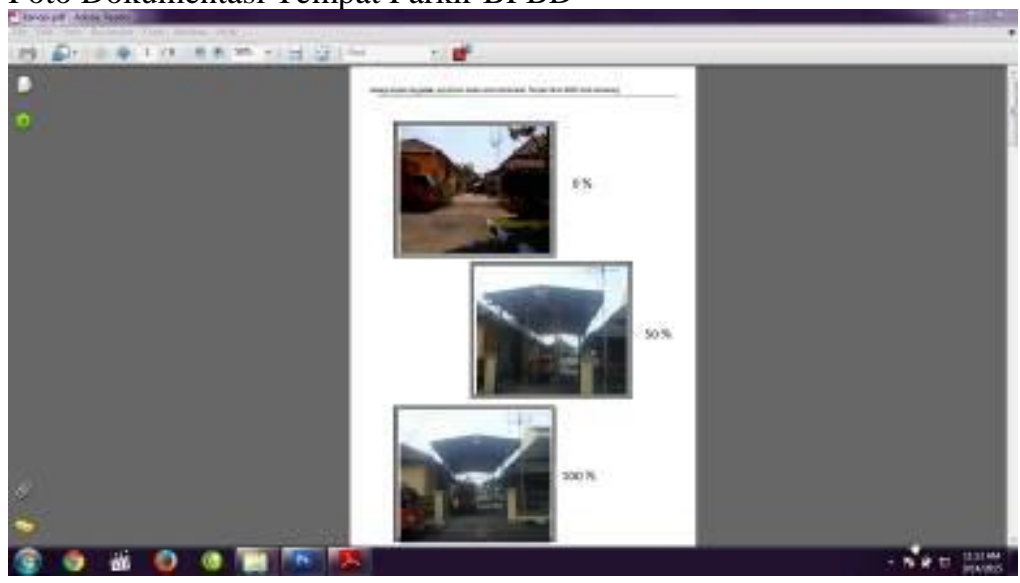

Gambar 4.40 Foto Dokumentasi Tempat Parkir BPBD

g) Garasi Balatrans

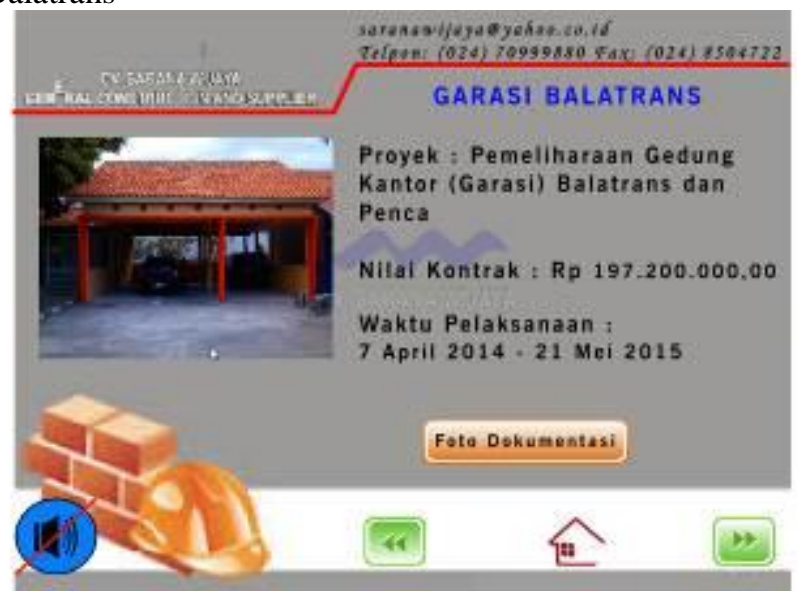

Gambar 4.41 Tampilan Akhir Garasi Balatrans 
h) Foto Dokumentasi Garasi Balatrans

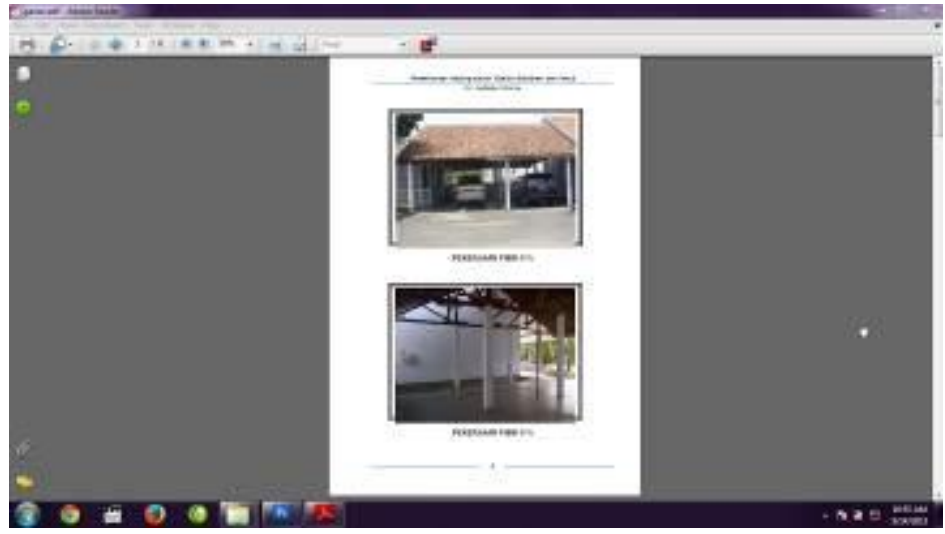

Gambar 4.42 Tampilan Akhir Foto Dokumentasi Garasi Balatrans

i) Pavingisasi Sembungharjo

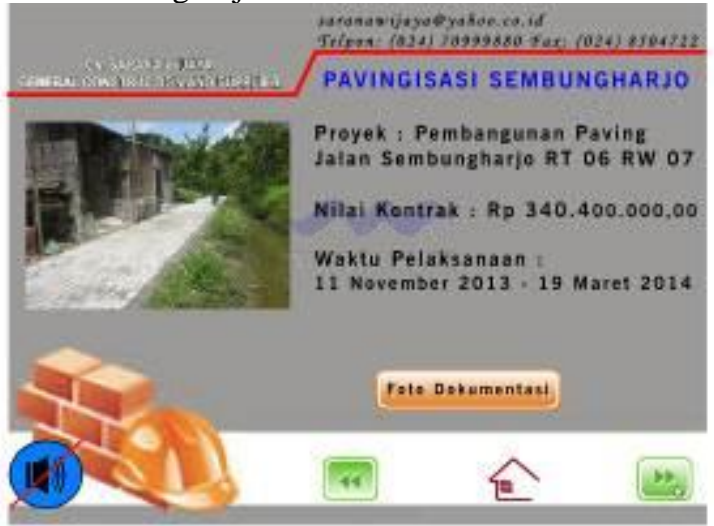

Gambar 4.43 Tampilan Akhir Garasi Balatrans

j) Foto Dokumentasi Pavingisasi Sembungharjo

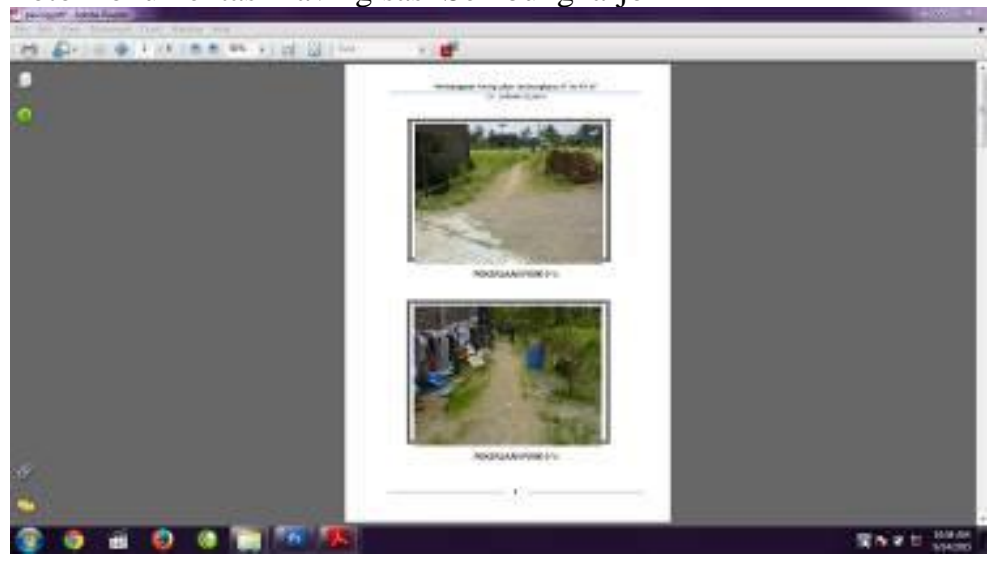

Gambar 4.44 Tampilan Akhir Foto Dokumentasi Pavingisasi Sembungharjo 
k) Gedung Balatrans

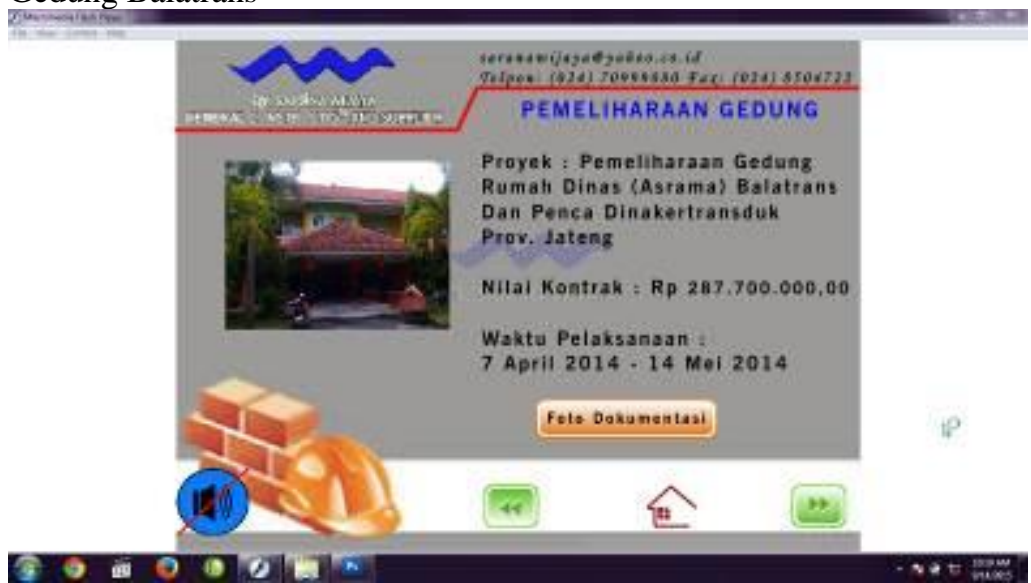

Gambar 4.45 Tampilan Akhir Foto Dokumentasi Gedung Balatrans

1) Foto Dokumentasi Gedung Balatrans

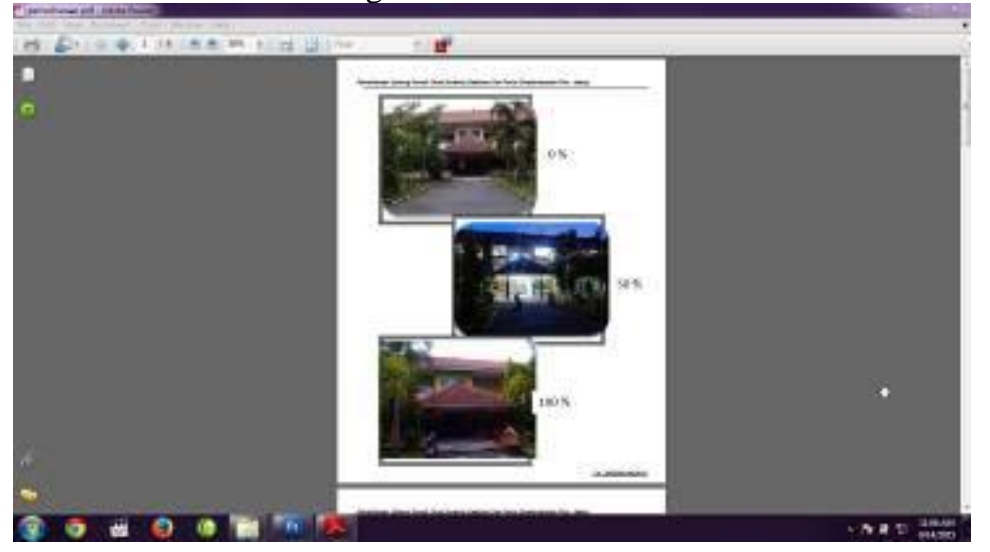

Gambar 4.46 Tampilan Akhir Foto Dokumentasi Gedung Balatrans

2. Software dan Hardware Untuk Membuka Company Profile

a. Software

Pengertian Software komputer adalah perangkat lunak komputer untuk mengkontrol perangkat keras. Bisa juga diartikan sebagai data yang diprogram dan disimpan secara digital dalam bentuk aplikasi, termasuk program komputer, dokumentasinya, dan berbagai informasi yang bisa dibaca dan ditulis oleh komputer. Dengan kata lain, bagian sistem komputer yang tidak berwujud. Software yang bisa digunakan untuk membuka company profile ini adalah:

1) Flash Player

Ini adalah software unutk memainkan file flash (swf), tapi software ini bukan hanya dapat membuka dan memainkan file flash dengan extension filenya swf saja , tetapi juga dapat memainkan file-file video atau file animasi lainnya. Seperti contohnya file video dengan extension filenya FLV, 3GP, MP4, AVI, MKV, WMV dan file video lainnya. Selain dapat memainkan file-file video dan animasi, juga software free flash player ini mampu membuka serta memutar file audio, format audio yang didukung Untuk jenis extension file audio yang dapat didukung oleh software ini di antaranya ialah WMA, WAV, MP3, MP2, AC3, AAC dan OGG, juga dapat unutk melihat file gambar.

2) Flash Movie Player

Software ini hampir sama dengan software lainnya, dan hanya bisa untuk file flash. juga dapat convert (swf) ke (exe).

b. Hardware

Hardware atau biasa disebut dalam Bahasa Indonesia "Perangkat Keras" merupakan kumpulan elemen atau komponen fisik yang menyusun suatu sistem komputer. Secara garis besar, Hardware dibagi menjadi tiga kelompok berdasarkan cara kerjanya, yaitu input 
(masukan), process (pemrosesan), output (keluaran). Hardware yang di gunakan dalam proses membuka company profile ini adalah:

1) Layar LCD: untuk menampilan gambar

2) Keyboard: Untuk Input data ke dalam computer

3) Speaker Internal kiri dan kanan (stereo audio output).

4) Keyboard: untuk Input data ke dalam komputer

\section{KESIMPULAN}

Dari penjelasan di atas dan penguraian bab-bab sebelumnya, maka dapat ditarik kesimpulan sebagai berikut:

1. Company Profile CV. Sarana Wijaya dinilai sangat membantu perusahaan dalam penyebaran informasi, karena pada media ini terdapat penjabaran tentang CV. Sarana Wijaya seperti profil perusahaan, profil direktur, tujuan, visi \& misi, gallery pengalaman kerja dan peralatan yang dimiliki CV. Sarana Wijaya.

2. Company Profile CV. Sarana Wijaya berguna untuk mengembangkan perusahaan dengan menggunakan teknologi multimedia agar dapat menjalin kerjasama dengan perusahaan yang lebih banyak.

\section{DAFTAR PUSTAKA}

[1] Alfa, Faizal Z. 2010. "Fungsi Company Profile", www.panduancompanyprofile.wordpress.com/2010/03/24/fungsi-company-profile-companyprofile-function/. (diakses tanggal 27 April 2021)

[2] Ariasdi. 2008. "Warna Itu Yernyata Berwarna-Warna", https://ariasdimultimedia.wordpress.com/2008/03/20/warna-itu-ternyata-berwarna-warna. (diakses tanggal 27 April 2021)

[3] Arsad, Arfial. 1984. "Nirmana Dwimatra (Desain Dasar Dwimatra)". Andi. Yogyakarta.

[4] Akbar, Muh. 2006. "Pengertian Company Profile". http://cetak.fajar.co.id/news.php?newsid=74528. (diakses tanggal 27 April 2021)

[5] Binasyifa, 2015. "Unsur Company Profile", www.binasyifa.com/319/63/26/unsur-companyprofile.htm. (diakses tanggal 27 April 2021)

[6] Binanto, Iwan. 2010. "Multimedia Digita". Andi. Yogyakarta.

[7] Echolas, John M. 1976. "AN English-Indonesian Dictionary (Kamus Inggris-Indonesia)”. PT Gramedia. Jakarta.

[8] Kusrianto, Adi. 2007. "Pengantar Desain Komunikasi Visual”. Andi. Yogyakarta

[9] Muhuck. 2011. "Pengertian Tipografi Dalam Web Design", https://muhuck.wordpress.com/2011/12/04/pengertian-tipografi-dan-tipografi-dalam-webdesign/. (diakses tanggal 27 April 2021)

[10] Prisma Haris, Nuryawan. 2009. "Kombinasi Warna Komplementer”. PT Gramedia. Jakarta Barat.

[11] Rahman, Yanuar. 2011. "Multimedia Interaktif", www.slideshare.net/vidiyan/multimediainteraktif. (diakses tanggal 27 April 2021)

[12] Rustan, Surianto. 2008. "Layout, Dasar \& Penerapannya”. PT Gramedia.

[13] Jakarta Barat

[14] Sihombing, Danton. 2001. "Tipografi dalam Desain Grafis". Gramedia Pustaka Utama. Jakarta

[15] Sipahelut, Atisah. 1995. "Seni Rupa dan Desain”. Erlangga. Jakarta

[16] Siska, Iyanka. 2013. "Sejarah dan Pengertian Multimedia", www.iyanksicksoul.wordpress.com/2013/03/30/sejarah-dan-pengertian-multimedia//. ～(diakses tanggal 27 April 2021)

[17] Syaifurrahman. 2014. "Pengertian Software Computer Paling Lengkap", www.webberbagi.blogspot.com/2014/10/pengertian-software-komputer-palinglengkap.html\#.VXOhBNLtmko. (diakses tanggal 27 Mei 2021)

[18] Takeitfun. 2010. www.takeitfun.blogdetik.com. (diakses tanggal 27 April 2021)

[19] Vicky. 2011. "Pengertian Hardware (Perangkat Keras) Komputer" www.belajar-komputermu.com/pengertian-hardware-perangkat-keras-komputer/. (diakses tanggal 27 Mei 2021)

[20] Wijanarko, Lizard. 2010. "Teori warna", www.ahlidesain.com/teori-warna.html. (diakses tanggal 27 April 2021)

[21] Wikipedia. 2015. "Pengertian Exe", www.wikipedia.org/wiki/EXE. (diakses tanggal 27 April 2021) 
[22] Wikipedia. 2015. "Pengertian Warna", www.wikipedia.org/wiki/Warna. (diakses tanggal 27 April 2021) 